\title{
INFLUENCE OF CARBON CONTENT ON FATIGUE STRENGTH OF DRAWN STEEL TUBES FOR SMALL ONCE-THROUGH BOILER
}

\author{
DAISUKE YONEKURA \\ Department of Mechanical Engineering, The University of Tokushima, 2-1 Minami-josanjima \\ Tokushima, Tokushima 770-8506, Japan \\ yonekura@me.tokushima-u.ac.jp \\ YUTA FUJIE \\ School of Mechanical Engineering, The University of Tokushima, 2-1 Minami-josanjima \\ Tokushima, Tokushima 770-8506, Japan \\ RI-ICHI MURAKAMI \\ Department of Mechanical Engineering, The University of Tokushima, 2-1 Minami-josanjima \\ Tokushima, Tokushima 770-8506, Japan \\ murakami@me.tokushima-u.ac.jp \\ YUKIHIRO TOKUNAGA \\ MIURA INSTITUTE of RESEARCH \& DEVELOPMENT, Horie 7 \\ Matsuyama, Ehime 799-2696, Japan \\ tokunaga_yukihiro@miuraz.co.jp
}

\begin{abstract}
Tension-tension fatigue tests were performed to examine the influence of carbon content on the fatigue properties of drawn specific steel tube (STB340) with/without post heat treatment for small once-through boiler. Two different carbon content steel tubes, $\mathrm{C}=0.06$ and $0.12 \%$ were prepared. The as-received, as-drawn and post drawing heat treated series for each carbon content tube were prepared for fatigue test. The hardness, grain size and residual stress were measured for each series. As a result, the fatigue strength of as-received and as-drawn series showed a small difference between $\mathrm{C}=0.06$ and $0.12 \%$ specimens. However, the post drawing heat treatment series showed obvious difference in the fatigue strength. The fatigue strength of higher carbon content tubes significantly decreased by the post drawing heat treatment, whereas the decrease of fatigue strength was little for lower carbon content heat treated tubes. The difference of fatigue strength was mainly caused by the degree of relaxation of work hardening by post heat treatment.
\end{abstract}

Keywords: Fatigue; carbon content; drawing; specific steel tube.

\section{Introduction}

A small once-through boiler is classified as an industrial boiler with maximum equivalent evaporation of $2,000 \mathrm{~kg} / \mathrm{h}$. The small once-through boiler has many heat exchanger tubes. The tubes are formed into appropriate outside diameter by drawing process before 
assembly. Since the steel for heat exchanger tube requires sufficient corrosion resistance and formability, the carbon content in the steel tubes is appropriately controlled. It is well known that the carbon content has a great influence on the fatigue properties of steel as well as the formability and heat treatment characteristics. The heat exchanger tubes are formed by drawing process and then, post drawing heat treatment is also carried out. Therefore, carbon content will also have a strong influence on the fatigue properties of heat exchanger tubes. The influence of post heat treatment is particularly important, which causes a detrimental or negligible effect on the mechanical properties as well as beneficial effect due to the change of micro structure of the steel, softening and releasing the compressive residual stress in the loading direction. ${ }^{1-4}$

In general, cyclic thermal stress is generated in the tubes by starting/stopping the boiler. The thermal stress causes fatigue failure from the drawn and welded part in the heat exchanger tubes. ${ }^{5}$ We previously examined the influence of post drawing heat treatment on the fatigue properties of a steel tube for small once-through boiler, using a STB340 special steel tube with $\mathrm{C}=0.06 \%{ }^{6}$ As a result, the fatigue strength after post drawing heat treatment was clearly higher than that of the as-received specimens, although the heat treatment temperature and time were sufficient to anneal. In this study, we examined the influence of carbon content in steel tubes for the small once-through boiler on the fatigue strength using as-received, as-drawn and post drawing heat treated steel tubes.

\section{Experimental Procedure}

Steel tubes for a small once-through boiler, STB340 which is special steel for boiler, were used as a material. In our previous study, we used a STB340 steel tube having $\mathrm{C}=0.06 \%{ }^{6}$ In this study, we prepared a different carbon content tube having $0.12 \%$ and compared the fatigue properties with the case of $\mathrm{C}=0.06 \%$. The chemical composition and the mechanical properties of the tubes are shown in Table 1. The tubes were formed from $60.3 \mathrm{~mm}$ to $45.2 \mathrm{~mm}$ in outside diameter by a drawing process. After the drawing process, post drawing heat treatment (PDHT) was performed at $898 \mathrm{~K}$ for 2 hours with furnace cooling. The fatigue specimens were made by cutting the as-drawn and post heat treated tubes, respectively. The specimen shape is shown in Fig.1, where the area of $50 \times 20 \mathrm{~mm}$ was pressed into a flat shape for chucking. As-received tubes were also machined into the same shape as a reference material. These specimens were named "asdrawn", "PDHT" and "as-received" series, respectively.

Table 1 Chemical composition and $0.2 \%$ proof stress of as-received specimens.

\begin{tabular}{|c|c|c|c|c|c|c|c|c|}
\hline & \multicolumn{6}{|c|}{ Chemical composition, $\mathrm{wt} \%$} & \multirow{2}{*}{$0.2 \%$ proof stress, $\mathrm{MPa}$} \\
\hline & & $\mathrm{C}$ & $\mathrm{Si}$ & $\mathrm{Mn}$ & $\mathrm{P}$ & $\mathrm{S}$ & $\mathrm{Fe}$ & \\
\hline \multirow{2}{*}{ 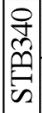 } & $\mathrm{C}=0.06 \%$ & 0.06 & 0.11 & 0.53 & 0.008 & 0.002 & Bal. & 257 \\
\hline & $\mathrm{C}=0.12 \%$ & 0.12 & 0.22 & 0.48 & - & - & Bal. & 262 \\
\hline
\end{tabular}




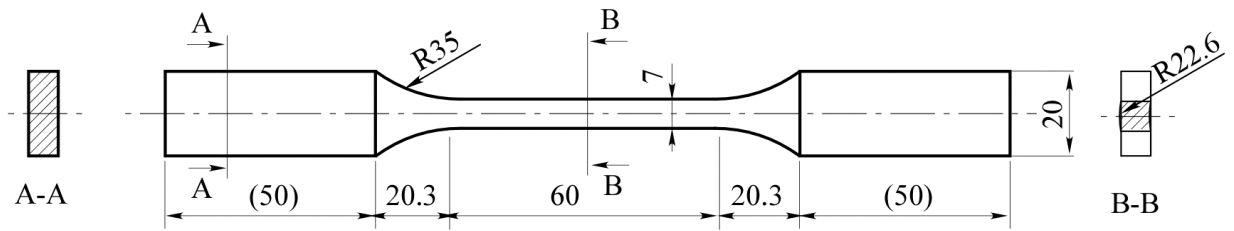

Fig. 1 Specimen configuration.

Tension-tension fatigue tests were performed using these specimens under load controlled conditions in air using a material testing system (MTS Systems Co., TestStar II) operated at a frequency of $10 \mathrm{~Hz}$. The stress ratio was $R=\sigma_{\min } / \sigma_{\max }=0.05$, where $\sigma_{\max }$ and $\sigma_{\min }$ are the maximum and minimum stress during cyclic loading. Stress level at which a specimen can run without occurrence of failure after $10^{7}$ stress cycles was chosen as an endurance limit.

The fatigue properties were discussed on the basis of fractography, hardness, residual stress and grain size for each series. The fracture surface was observed using SEM. The micro hardness of the each series was measured by the 50 points average using a Vickers microhardness tester under $490 \mathrm{mN}$. The residual stress of the outer and inner surfaces was measured by parafocusing method using $\mathrm{Fe}$ (311) diffraction with $\mathrm{CrK} \alpha$ characteristic X-rays and $2 \theta-\sin ^{2} \psi$ method. The tube voltage was $35 \mathrm{kV}$, and the tube current was $20 \mathrm{~mA}$. The grain size was measured on the etched cross section to the loading direction using $9 \%$ nital solution.

\section{Experimental Results and Discussions}

\subsection{Hardness, Grain Size and Residual Stress}

Figure 2 shows the hardness and the grain size of each series. The hardness of both $\mathrm{C}=0.06 \%$ and $0.12 \%$ specimens increased uniformly after drawing process by work hardening as shown in Fig. 2 (a). The difference of the hardness between as-received and as-drawn series was about $10 \mathrm{HV}$ regardless of the carbon content. This result indicates carbon content has a little influence on the hardness for as received and as-drawn series. In contrast, the carbon content obviously affected the hardness for the PDHT series. The hardness was reduced after PDHT process, and significantly for $\mathrm{C}=0.12 \%$ specimens. The high carbon content specimen is, therefore, easy to be softened due to recrystallization by PDHT. Figure 2 (b) shows the cross sectional grain size for each carbon content specimens. The cross sectional grain size decreased after drawing process for both carbon contents due to the plastic deformation of grains. However, the decrease in grain size for $\mathrm{C}=0.12 \%$ specimens was smaller than that for $\mathrm{C}=0.06 \%$ specimens. After PDHT process, grain size increased for both carbon contents. The increase for $\mathrm{C}=0.12 \%$ specimens was slightly larger than that for $\mathrm{C}=0.06 \%$ specimens. Higher carbon content, therefore, has a little effect on the change of grain size by drawing process, whereas grain size for higher carbon content specimen is slightly easy to become coarse by PDHT process. 

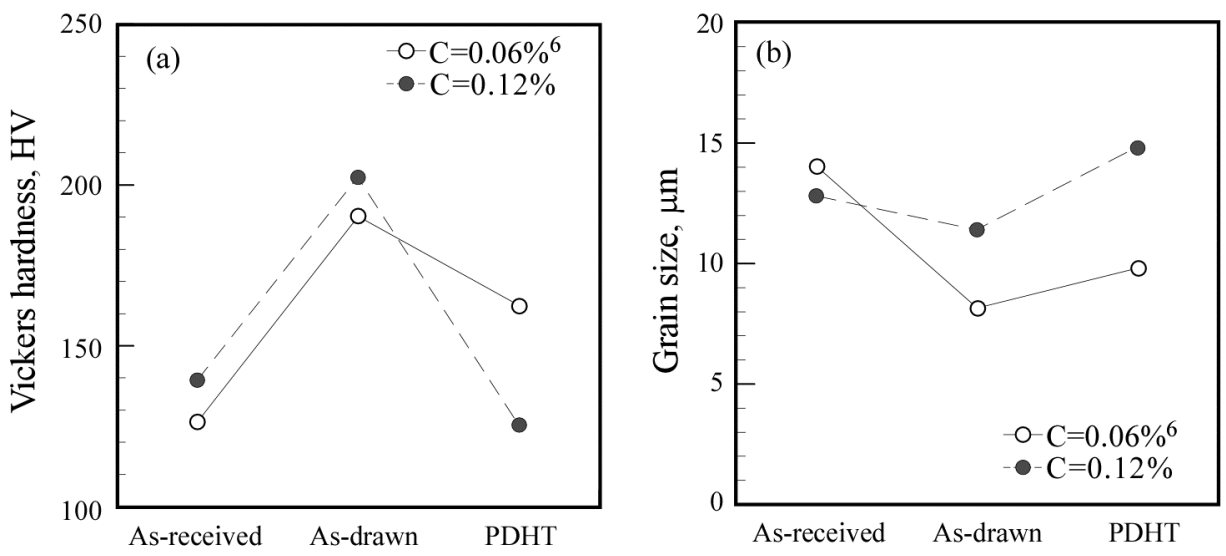

Fig. 2 Hardness and cross sectional grain size.

The result of residual stress measurement is summarized in Fig. 3. In the case of asreceived series of $\mathrm{C}=0.06 \%$ specimens, the axial residual stress was compressive, which was about $-150 \sim-170 \mathrm{MPa}$ on the both outer and inner surfaces. The compressive residual stress decreased by drawing and PDHT processes and the lowest compressive residual stress of about -20 MPa was measured on the inner surface after PDHT process. In the case of $C=0.12 \%$ specimens, the axial residual stresses on the outer surface were compressive, which was about -80 MPa. However, the axial residual stress was tensile on the inner surface. After drawing process, the tensile residual stress was still measured on the inner surface. The residual stress was finally changed to compressive by PDHT, however the stress level was quite low. On the other hand, the circumferential residual stresses were also generated. The circumferential residual stresses were compressive and they were obviously higher than axial stress. The circumferential residual stress was insensitive to the drawing and PDHT process.

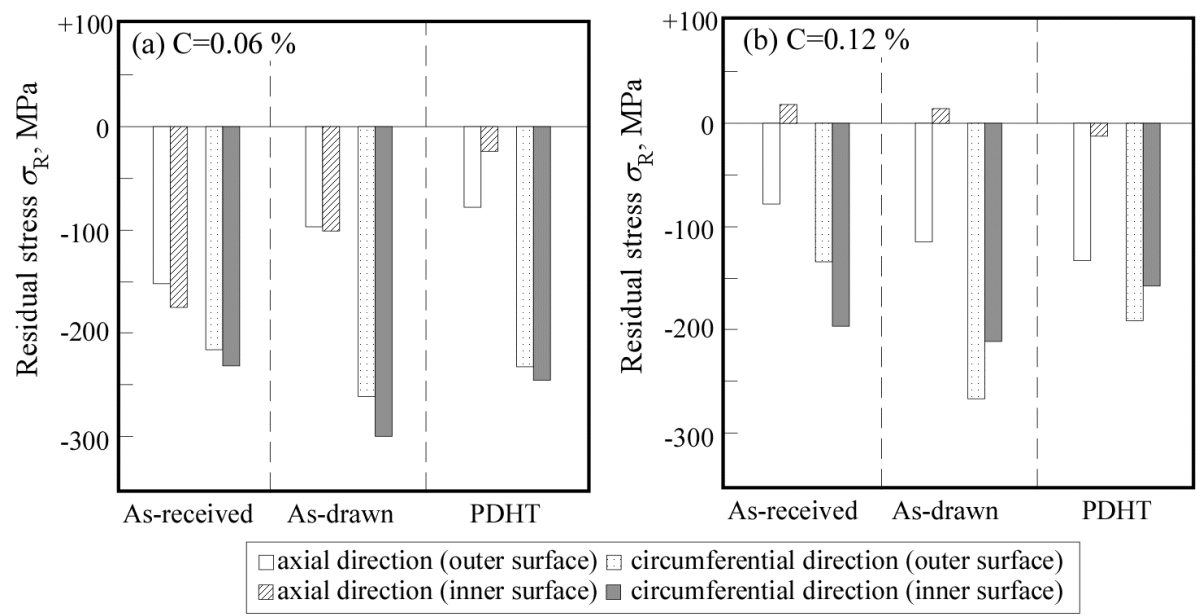

Fig. 3 Summary of residual stress measurement. 


\subsection{Fatigue Test}

Tension-tension fatigue tests were carried out using the specimens having two different carbon contents. Figure 4 (a) (c) shows the S-N curves of as-received, as-drawn and post heat treated series, respectively. For all specimens, the fatigue crack initiated from inner surface where the lower axial compressive residual stress was generated compared with outer surface. In the case of as-received series, the carbon content hardly affected the fatigue strength as shown in Fig. 4(a). After drawing process (Fig. 4 (b)), the fatigue strength of $\mathrm{C}=0.12 \%$ specimens was also similar to the strength of $\mathrm{C}=0.06 \%$ specimens except for $\sigma_{\mathrm{a}}>250 \mathrm{MPa}$. In contrast, the carbon content had a great influence on the fatigue strength when the PDHT process was carried out as shown in Fig. 4(c). The fatigue strength of $\mathrm{C}=0.12 \%$ PDHT series was clearly lower than that of $\mathrm{C}=0.06 \%$ PDHT series. In addition, the fatigue strength of $\mathrm{C}=0.12 \%$ PDHT series was lower than asreceived series of same carbon content, although the fatigue strength of $\mathrm{C}=0.06 \%$ PDHT specimens was higher than as-received series of $\mathrm{C}=0.06 \%$.
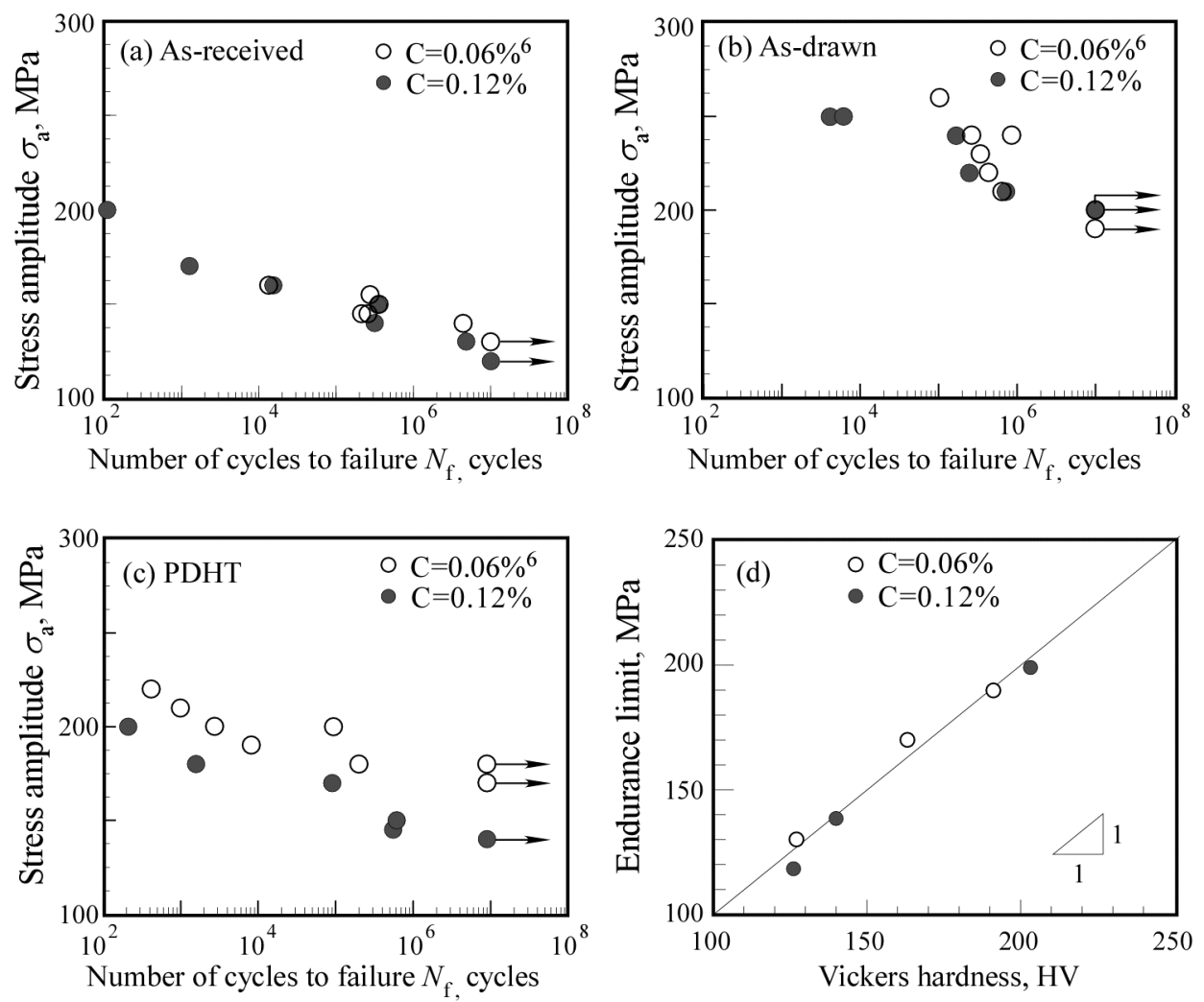

Fig. 4 Result of fatigue tests; (a) (c) $S$ - $N$ curves for each series and (d) relationship between Vickers hardness and endurance limit. 
Figure 4(d) shows the relationship between Vickers hardness and endurance limit of both carbon content specimens. The result shows a good agreement between the plots and the linear regression line which has a slope of 1.0 regardless of the carbon content and the process, although the each series has different residual stress and grain size. This result suggests that the hardness is the predominant factor in determining the endurance limit and residual stress and grain size had a little influence on the endurance limit.

It is concluded that the appropriate carbon content in STB340 steel should be decided on the basis of the specimen hardness after drawing and post drawing heat treatment.

\section{Conclusions}

In this study, we examined the influence of carbon content of steel for a small oncethrough boiler on the fatigue strength using as-received, as-drawn and post drawing heat treated steel tubes. The results are summarized as follows:

(i) Carbon content in STB340 steel affected the hardness after post drawing heat treatment process. The carbon content also had an influence on the axial residual stress of inner surface.

(ii) Carbon content affected the fatigue strength of post drawing heat treated STB340 steel, whereas the influence on the fatigue strength was little for as-received and asdrawn STB340 steel.

(iii) The linear regression showed a good agreement between Vickers hardness and endurance limit regardless of the carbon content.

\section{References}

1. C. Smith, P. G. H. Pistorius and J. Wannenburg, Int. J. Pred. Ves. \& Piping, 70, 183 (1997).

2. M.C. Young, L.W. Tsay, C.-S. Shin and S.L.I. Chan, Int. J. Fatigue 29, 2155 (2007).

3. S. Ravi, V. Balasubramanian and S. Nemat Nasser, Int. J. Fatigue 27, 547 (2005).

4. A. Fissolo, C. Gourdin, O. Ancelet, S. Amiable, A. Demassieux, S. Chapuliot, N. Haddar, F. Mermaz,J.M. Stelmaszyk, A. Constantinescu, L. Vincent and V. Maillot, Int. J. Fatigue 31, 1196 (2009).

5. Y. Tokunaga, N. Yan, D. Yonekura and R. Murakami., Key Engineering Materials 353-358, 315 (2007).

6. D. Yonekura, Y. Fujie, H. Nishii, H. Yamakawa and R. Murakami, Advanced Materials Research 275, 109 (2011). 